\title{
Susceptibility pattern of Salmonella enterica against commonly prescribed antibiotics, to febrile-pediatric cases, in low-income countries
}

\author{
Priyatam Khadka ${ }^{1 *}$, Januka Thapaliya ${ }^{1}$ and Shovana Thapa²
}

\begin{abstract}
Background: In most low-income countries, febrile-pediatric-cases are often treated empirically with accessible antibiotics without periodic epidemiological surveillance, susceptibility testing, or minimal lethal dose calculations. With this backdrop, the study was undertaken to evaluate the susceptibility trend of Salmonella enterica against the commonly prescribed antibiotics.

Methods: All isolates of Salmonella enterica were identified by standard protocols of biotyping and serotyping, then tested against antibiotics by the modified Kirby disk-diffusion method. Minimum Inhibitory Concentration (MIC) of isolates was determined by the agar-dilution method and compared with disk diffusion results and on nalidixic-acid sensitive/resistant strains.

Results: Among 1815 febrile-pediatric patients, 90(4.9\%) isolates of Salmonella enterica [serovar: Salmonella Typhi 62(68.8\%) and Salmonella Paratyphi A 28(31.1\%)] were recovered. The incidence of infection was higher among males, age groups 5 to 9, and patients enrolling in the out-patient department (OPD). On the disk-diffusion test, most isolates were sensitive against first-line drugs i.e.cephalosporins, and macrolides. However, against quinolones, a huge percentile 93.3\%, of isolates were resistant [including 58 Typhiand 26 Paratyphiserovar] while nearly 14\% were resistant against fluoroquinolones.

When MICs breakpoint were adjusted as follows: $4 \mu \mathrm{g} / \mathrm{ml}$ for azithromycin, $\geq 1 \mu \mathrm{g} / \mathrm{ml}$ for ciprofloxacin, $2 \mu \mathrm{g} / \mathrm{ml}$ for ofloxacin, $8 \mu \mathrm{g} / \mathrm{ml}$ for nalidixic acid, and $1 \mu \mathrm{g} / \mathrm{ml}$ for cefixime, higher sensitivity and specificity achieved. Compared to other tested antibiotics, a low rate of azithromycin resistance was observed. Nevertheless, higher resistance against fluoroquinolones was observed on NARS strain.

Conclusion: Higher susceptibility of Salmonella enterica to the conventional anti-typhoidal drugs (amoxicillin, chloramphenicol, cotrimoxazole, cephotaxime) advocates for its reconsideration. Although, the lower susceptibility against fluoroquinolones among nalidixic-acid-resistant Salmonella (NARS) strain negates its empirical use among the study age group.
\end{abstract}

Keywords: Enteric fever, Low-income countries, Nepal, Pediatric, Salmonella enterica

\footnotetext{
* Correspondence: khadka.priyatam@gmail.com

${ }^{1}$ Medical Microbiology, Tri-Chandra Multiple Campus, Kathmandu, Nepal

Full list of author information is available at the end of the article
}

(C) The Author(s). 2021 Open Access This article is licensed under a Creative Commons Attribution 4.0 International License, which permits use, sharing, adaptation, distribution and reproduction in any medium or format, as long as you give appropriate credit to the original author(s) and the source, provide a link to the Creative Commons licence, and indicate if changes were made. The images or other third party material in this article are included in the article's Creative Commons. licence, unless indicated otherwise in a credit line to the material. If material is not included in the article's Creative Commons licence and your intended use is not permitted by statutory regulation or exceeds the permitted use, you will need to obtain permission directly from the copyright holder. To view a copy of this licence, visit http://creativecommons.org/licenses/by/4.0/ The Creative Commons Public Domain Dedication waiver (http://creativecommons.org/publicdomain/zero/1.0/) applies to the data made available in this article, unless otherwise stated in a credit line to the data. 


\section{Background}

Enteric fever, a serious bloodstream infection caused by Salmonella enterica species, is a burgeoning global threatdisproportionately affecting more than 17 million people with recorded mortality 178,000,000, annually [1-3]. The infection prevails irrespective of any age categories; nevertheless, children of low and middle-income countries have the highest documented burden [4-6]. Also, the most MDR (multi-drug resistant)strains(H58 strain) had recovered from these countries $[7,8]$. Therefore, the condition is excruciating, the people of these regions had to face the dual challenge of economic constraints and obstinate MDR strain. In Nepal, the MDR H58 Salmonella Typhi(S. Typhi) seems to have been substituted by non-MDR H58 carrying the S83F mutation in gyrA and other mutations-associated with reduced susceptibility to fluoroquinolones $[9,10]$. Likewise, Salmonella Paratyphi A(S.Paratyphi) frequently carries fluoroquinolone non-susceptibility alleles in gyrA and parC; however, none of these isolates were MDR $[11,12]$. Nevertheless, the possible transmissibility of MDR H58 could not be neglected since many cases of MDR $\mathrm{H} 58$ had been reported from the abutting countries: India, Pakistan, and Bangladesh [13, 14]. This background justifies the rationale of our study.

The infection is primarily treated by antimicrobial therapy; nonetheless, is becoming difficult due to changes in the susceptibility trend of the pathogen. Ironically, without a periodic epidemiological survey, susceptibility testing, and minimal lethal dose calculations; children in developing countries are still being treated empirically or even self-medicated with accessible antibiotics [15]. These could be the reasons, why there is significant morbidity and mortality in most developing countries [3, 16, 17]. Therefore, in these countries, where distinct diagnostic and therapeutic modalities could not be assessed due to economic constraints, evaluating antimicrobial susceptibility pattern of the isolate against commonly prescribed antibiotics is crucial for clinical management.

\section{Methods}

\section{Study design and sample population}

A cross-sectional study was conducted over one year (April 2017-March 2018) in International Children Friendship Hospital (ICFH), a tertiary care hospital for children, in Kathmandu, Nepal. Febrile-pediatric subjects (up to 14 years of age) with clinical suspicion of enteric fever were enrolled, in our study. The clinical investigation/ suspicion to enteric fever was made by the respective unit pediatrician, relying upon the clinical history and most occurring clinical presentations-high-grade fever, abdominal pain, sore throat, loss of appetite, and generalized weakness. A pre-tested questionnaire was administered to each patient or from their guardian to ascertain demographic characteristics, symptoms, brief clinical history, and history of antibiotic use (if under therapy). Furthermore, commonly prescribed antibiotics (either from clinicians or in self-medicated cases) for enteric fever, in the record of local pharmacies, were evaluated. Data regarding personal information (patient's demographic including residence locality) and existing other infectious diseases were coded and kept confidential.

\section{Inclusion and exclusion criteria}

All febrile-pediatric patients with clinical suspicion of enteric fever were enrolled; however, only Salmonella enterica recovered from blood samples were studied. The other isolates, nonetheless, obtained from the sample (other than blood) after a period, and from the same patient were considered as duplicated isolates, hence excluded.

\section{Laboratory methods}

The blood samples were collected aseptically (about 2-3 $\mathrm{ml}$ ) and cultured in brain heart infusion broth (HiMedia, India) as per guidelines set by the American Society for Microbiology (ASM) for conventional blood culture [18]. Further, isolation and identification of the isolates were done by standard microbiological techniques-biotyping (colony morphology, staining reaction, and biochemical characteristics) and serotyping using specific antisera (Denka Seiken Co. Ltd., Tokyo, Japan) [18]. The samples were considered sterile if no bacterial growth was observed on the sub-culture after 7 days of aerobic incubation at $37^{\circ} \mathrm{C}$.

\section{Antimicrobial susceptibility testing}

The antimicrobial susceptibility of Salmonella enterica against antibiotics was tested by the disk diffusion method [modified Kirby-Bauer method] on Mueller Hinton agar (Hi-Media, India) in compliance with standard procedures recommended by the Clinical and Laboratory Standards Institute (CLSI), Wayne, PA, USA [19]. The antimicrobials tested were: amoxicillin $(10 \mu \mathrm{g})$, azithromycin $(15 \mu \mathrm{g})$, cefixime $(5 \mu \mathrm{g})$, ceftriaxone $(30 \mu \mathrm{g})$, cephotaxime $(30 \mu \mathrm{g})$, chloramphenicol $(30 \mu \mathrm{g})$, ciprofloxacin $(5 \mu \mathrm{g})$, cotrimoxazole $(25 \mu \mathrm{g})$, nalidixic-acid $(30 \mu \mathrm{g})$, ofloxacin $(5 \mu \mathrm{g})$. The interpretation of susceptibility results was made based on interpretative zone diameters suggested by CLSI. For the standardization of susceptibility testing, Escherichia coli ATCC (American Type Culture Collection) 25,922 and Staphylococcus aureus ATCC 25923 were used as control organisms.

\section{Determination of minimum inhibitory concentrations (MICs)}

Only, MICs of most prescribed antibiotics-recommended by clinicians, and self-medicated cases-recorded in the local pharmacies were done. MICs of ciprofloxacin, 
ofloxacin, nalidixic-acid, azithromycin, and cefixime were determined by agar dilution method as suggested by Andrews [20] based on CLSI guidelines [19]; and were classified sensitive or resistant accordingly. Of the total 90 isolates, MICs value of only 71 isolates were determined by the agar dilution method since 9 of the isolates were not preserved and 10 isolates could not be revived.

\section{Comparison between disk-diffusion test and MICs}

The results of disk-diffusion test and agar dilution test of the most commonly prescribed antibiotics (azithromycin, cefixime, ciprofloxacin, ofloxacin, and nalidixic-acid) were compared by WHONET 5.4 software.

\section{Correlation between NARS and fluoroquinolones (FQs)}

The obtained isolates were broadly classified into nalidixic-acid sensitive Salmonella (NARS) strains and nalidixic-acid sensitive Salmonella (NASS) strains and correlated against the resistance pattern of FQs.

\section{Data management and analysis}

The data obtained was entered in Microsoft Office Excel 2007 and analyzed by Statistical Package for Social Sciences (SPSS) version 16.0. The susceptibility data (with observed zone size) and MIC values of ciprofloxacin, ofloxacin, nalidixic-acid, azithromycin, and cefixime were analyzed by WHONET 5.4 software.

\section{Result}

\section{Patients' demographics}

During the study period, a total of 1815 febrile-pediatric patients, suspected to have enteric fever (including 997 male and 818 female patients) were enrolled. Of the total study population, the culture positivity rate was higher in males 55 (5.5\%) compared to females 35 (4.2\%). Similarly, the percentage was higher among the patient of age-group (5 to 9 years) and those from out-patient department (OPD). Before attending to hospital, 304 (218 on ciprofloxacin; 86 ofloxacin) had a self-medicated history, they visited our hospital when there was no symptomatic resolution (Table 1 ).

\section{Bacterial isolates}

Of total samples, $4.9 \%(n=90)$ Salmonella enterica isolates were recovered, among them 62(68.8\%) were S. Typhi and the remaining 28 (31.1\%) were S.Paratyphi.

\section{Antibiogram of Salmonellaenterica isolates on disk- diffusion test}

On susceptibility testing, most of the recovered isolates were sensitive to first-line antibiotics (amoxycillin, chloramphenicol, and cotrimoxazole), third-generation cephalosporins (cephotaxime, ceftriaxone, and cefixime), and macrolides (azithromycin). However, to FQs, 93.3\% of the isolate were quinolone-resistant and nearly $15 \%$ were resistant to ciprofloxacin and ofloxacin (Table 2).

\section{Antibiogram of Salmonella enterica based upon MICs}

Susceptibility results of 71 isolates were tested for MIC of antibiotics: ciprofloxacin, ofloxacin, nalidixic-acid, cefixime, and azithromycin are shown in Table 3. The sensitive/resistant isolates were classified according to the CLSI guideline based upon the MICs of antibiotics.

Table 1 Patients' demographics

\begin{tabular}{|c|c|c|c|c|}
\hline \multirow[t]{2}{*}{ Patients demographics } & \multirow{2}{*}{$\begin{array}{l}\text { Total } \\
\text { suspected }\end{array}$} & \multirow{2}{*}{$\begin{array}{l}\text { Confirmed } \\
(\%)\end{array}$} & \multicolumn{2}{|c|}{ Salmonella enterica serovar } \\
\hline & & & Typhi (\%) & Paratyphi (\%) \\
\hline \multicolumn{5}{|l|}{ Gender } \\
\hline Male & 997 & $55(5.5)$ & $39(70.9)$ & $16(29.1)$ \\
\hline Female & 818 & $35(4.2)$ & $23(65.7)$ & $12(34.3)$ \\
\hline \multicolumn{5}{|l|}{ Age group } \\
\hline$<1$ year & 389 & $8(2.05)$ & $5(62.5)$ & $3(37.5)$ \\
\hline 1 to 4 years & 452 & $17(3.76)$ & $11(64.7)$ & $6(35.2)$ \\
\hline 5 to 9 years & 439 & $37(8.42)$ & $27(72.9)$ & $10(27.1)$ \\
\hline 10 to 14 years & 485 & $28(5.77)$ & $19(67.8)$ & $9(32.2)$ \\
\hline \multicolumn{5}{|l|}{ Patients distribution } \\
\hline Out-patient & 1389 & $73(5.2)$ & $53(72.6)$ & $20(27.4)$ \\
\hline In-patient & 426 & $17(3.9)$ & $12(70.59)$ & $5(29.41)$ \\
\hline \multicolumn{5}{|l|}{ Self-medicated history } \\
\hline Ciprofloxacin therapy & 218 & $6(2.7)$ & $5(83.3)$ & $1(16.7)$ \\
\hline Ofloxacin therapy & 86 & $4(4.6)$ & $3(75.0)$ & $1(25.0)$ \\
\hline
\end{tabular}


Table 2 Antimicrobial susceptibility pattern of Salmonella enterica on disk diffusion test

\begin{tabular}{|c|c|c|c|c|c|c|c|}
\hline \multirow[t]{3}{*}{ Antibiotics Group } & \multirow[t]{3}{*}{ Antibiotic used } & \multicolumn{6}{|c|}{ Antibiotic susceptibility } \\
\hline & & \multicolumn{2}{|c|}{ Susceptible } & \multicolumn{2}{|c|}{ Intermediate } & \multicolumn{2}{|c|}{ Resistant } \\
\hline & & $n$ & $\%$ & $n$ & $\%$ & $n$ & $\%$ \\
\hline penicillin & amoxycillin & 90 & 100 & 0 & 0 & 0 & 0 \\
\hline phenicols & chloramphenicol & 90 & 100 & 0 & 0 & 0 & 0 \\
\hline synthetic & cotrimoxazole & 90 & 100 & 0 & 0 & 0 & 0 \\
\hline \multirow[t]{3}{*}{ cephalosporins } & cephotaxime & 90 & 100 & 0 & 0 & 0 & 0 \\
\hline & ceftriaxone & 89 & 98.9 & 1 & 1.1 & 0 & 0 \\
\hline & cefixime & 89 & 98.9 & 1 & 1.1 & 0 & 0 \\
\hline macrolides & azithromycin & 88 & 97.8 & 2 & 2.2 & 0 & 0 \\
\hline \multirow[t]{3}{*}{ fluoroquinolones } & ofloxacin & 70 & 77.7 & 7 & 7.8 & 13 & 14.4 \\
\hline & ciprofloxacin & 65 & 72.2 & 13 & 14.4 & 12 & 13.3 \\
\hline & nalidixic-acid & 6 & 6.7 & 0 & 0 & 84 & 93.3 \\
\hline
\end{tabular}

\section{Ciprofloxacin MICs versus disk diffusion test}

41 isolates with MICs $\geq 0.5 \mu \mathrm{g} / \mathrm{ml}$ had ZOI (zone of inhibition) $\leq 28 \mathrm{~mm} ; 7$ isolates with $\mathrm{MICs} \geq 1 \mu \mathrm{g} / \mathrm{ml}$ and 1 isolate with $\mathrm{MIC}$ of $\geq 2 \mu \mathrm{g} / \mathrm{ml}$ had ZOI $22 \mathrm{~mm}$; among 22 isolates with $\mathrm{MICs} \leq 8 \mu \mathrm{g} / \mathrm{ml}, 10$ isolates had ZOI $\leq 17$ $\mathrm{mm}$ while the remaining had ZOI $\leq 15 \mathrm{~mm}$.

\section{Ofloxacin MICs versus disk diffusion test}

36 isolates with MICs $\leq 1 \mu \mathrm{g} / \mathrm{ml}$ had $\mathrm{ZOI} \geq 17 \mathrm{~mm}$ except one which had ZOI $12 \mathrm{~mm} ; 13$ isolates with MICs of $\leq 4 \mu \mathrm{g} / \mathrm{ml}$ had ZOI $17 \mathrm{~mm}$; of 22 isolates with MICs $\geq 8 \mu \mathrm{g} / \mathrm{ml}, 19$ isolates had ZOI $\leq 14 \mathrm{~mm}$ while the remaining are with $17 \mathrm{~mm} \mathrm{ZOI}$.

\section{Nalidixic acid MICs versus disk diffusion test}

58 isolates with MICs $\geq 32 \mu \mathrm{g} / \mathrm{ml}$ had ZOI $\leq 11 \mathrm{~mm}$; among 13 isolates with MICs $16 \mu \mathrm{g} / \mathrm{ml}, 9$ had ZOI $\geq 19$ $\mathrm{mm}$ while the remaining had ZOI $13 \mathrm{~mm}$.

\section{Cefixime MICs versus disk diffusion test}

44 isolates with MICs $\leq 0.5 \mu \mathrm{g} / \mathrm{ml}$ had $\mathrm{ZOI} \geq 19 \mathrm{~mm} ; 24$ isolates with MICs $\geq 1 \mu \mathrm{g} / \mathrm{ml}$ and $\leq 8 \mu \mathrm{g} / \mathrm{ml}$ had ZOI 19 $\mathrm{mm}$; of the remaining 3 isolates with MICs $\geq 32 \mu \mathrm{g} / \mathrm{ml}, 1$ isolate had ZOI $17 \mathrm{~mm}$ while the other 2 isolates had ZOI $19 \mathrm{~mm}$.

Table 3 Antimicrobial susceptibility pattern of Salmonella enterica based upon MICs

\begin{tabular}{|c|c|c|c|c|c|}
\hline \multirow{3}{*}{$\begin{array}{l}\text { Antibiotics } \\
\text { Group }\end{array}$} & \multirow{3}{*}{$\begin{array}{l}\text { Antibiotic } \\
\text { used }\end{array}$} & \multicolumn{4}{|c|}{ Antibiotic susceptibility } \\
\hline & & \multicolumn{2}{|c|}{ Susceptible } & \multicolumn{2}{|l|}{ Resistant } \\
\hline & & Number & $\%$ & Number & $\%$ \\
\hline macrolides & azithromycin & 70 & 98.6 & 1 & 1.4 \\
\hline cephalosporins & cefixime & 68 & 98.8 & 3 & 4.2 \\
\hline \multirow[t]{3}{*}{ fluoroquinolones } & ciprofloxacin & 49 & 69 & 22 & 31 \\
\hline & ofloxacin & 49 & 69 & 22 & 31 \\
\hline & nalidixic-acid & 13 & 18.3 & 58 & 81.7 \\
\hline
\end{tabular}

\section{Azithromycin MICs versus disk diffusion test}

67 isolates with MICs $\leq 8 \mu \mathrm{g} / \mathrm{ml}$ had ZOI $19 \mathrm{~mm} ; 3$ isolates with MICs $16 \mu \mathrm{g} / \mathrm{ml}$ had ZOI $18 \mathrm{~mm}$ while the remaining single isolate with MICs $64 \mu \mathrm{g} / \mathrm{ml}$ had ZOI $17 \mathrm{~mm}$.

The comparison of MIC and disk diffusion of these antibiotics is shown in Fig. 1.

Relying upon these results, MIC breakpoint was adjusted $4 \mu \mathrm{g} / \mathrm{ml}$ for azithromycin, $\geq 1 \mu \mathrm{g} / \mathrm{ml}$ for ciprofloxacin, $2 \mu \mathrm{g} / \mathrm{ml}$ for ofloxacin, $8 \mu \mathrm{g} / \mathrm{ml}$ for nalidixic-acid, and $1 \mu \mathrm{g} / \mathrm{ml}$ for cefixime; the zone of inhibition $19 \mathrm{~mm}, \leq 28$ $\mathrm{mm}, 17 \mathrm{~mm}, 19 \mathrm{~mm}, 19 \mathrm{~mm}$ for respective antibiotics was attained.

\section{Indicators of NARS with FQs}

The MICs of FQs (ciprofloxacin and ofloxacin) among NARS and NASS isolates are shown in Fig. 2. The scatter-plot correlating the MICs of ciprofloxacin, ofloxacin, and nalidixic-acid against Salmonella isolates are shown in the (supplemental fig. 1 and fig. 2). The plot reveals a simultaneous presence of reduced FQs susceptibility in NARS.

\section{Discussion}

The enteric fever or typhoid is one of the leading diagnosis of febrile illness in Nepal-a series of outbreaks with varying antimicrobial resistance trends have been reported [21-23]. Limited epidemiologic data with age categories up to 14 years are available; nevertheless, a pocket endemic region [24]. In these perspectives, estimation of the disease burden and its etiologies along with antimicrobial susceptibilities trend are obligatory factors requiring to effective prevention and control interventions.

The infection links strongly with low socio-economic status and unsanitary living conditions. Most of the urban areas of South Asia with growing population 


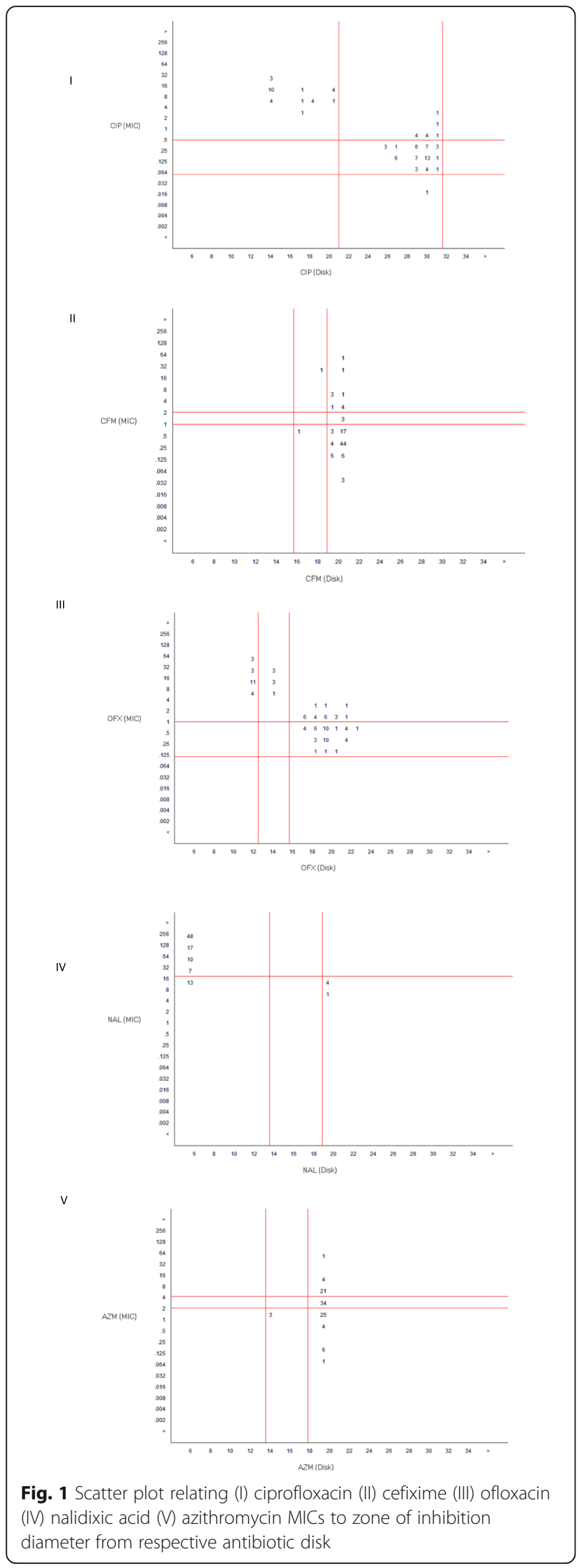

density and those lacking accessible safe water and food had sought as the high reservoirs [2, 3, 8, 25]. The highest incidence of salmonellosis up to $15.6 \%$ was recorded, in Nepal, including all age categories [26]. In pediatric population, we reported $4.9 \%$ culture-confirmed cases of Salmonella spp. which is more than twice the reported $2.0 \%$ by Prajapati et al. in 2008 [27]. The increasing rate could be due to surging population densities and lacking hygienic food/water supply in Kathmandu. Besides, a discrepancy in sample volume collected (particularly in infants and small kids where the required volume could not be drawn) as requires for culture could be one probable reason for the low rates of culture-positive enteric fever. Additionally, selfmedication prior to hospital arrival (often practiced in rural areas of Nepal) could be another factor contributing to the low culture-positivity rate. These antibiotics might have lowered the bacterial load (requiring to grow) but not had eradicated it. In our study, we noted many self-medicated cases with FQs.

While relating the age categories, the higher incidence of enteric fever was observed in age-group 5to 9 years (primary school-going children) in our study. The probable reason could be outside tiffin habits in local dhaba or hotels, where handwashing facilities are not available-even foods are also rarely fresh.

Turning to the epidemiological scenario, Salmonella Typhi (S.Typhi) is the causative agent of nearly $30 \%$ of community-acquired febrile illness in Asia and 10\% in Africa; but in Nepal, India, and China the predominance etiology contributing enteric fever is Salmonella Paratyphi (S.Paratyphi) [3, 7]. In our study, out of 90 cultureconfirmed cases of salmonellosis, 62(68.8\%) were caused by S. Typhi and the remaining 28 (31.1\%) were S. Paratyphi A. The predominance of serovar Typhi was found as per the observations made by Zellweger et al.68.5\% and $30.5 \%$ and Petersial et al. $55.7 \%$ and $44.3 \%$ respectively for serovars S. Typhi and S. Paratyphi [24, 25]. Shirakawa et al., nevertheless, reported S. Paratyphi as a more prevalent serovar [28]; his finding is corresponding to Pramod et al. (35.9\% S. Typhi and 64.1\% S. Paratyphi) [29]. There is no such well-established reason behind this variation of serovars; however, it can be assumed, the higher incidence of Typhi could be achieved via water-borne transmission as requires smaller inocula than paratyphoid which requires larger inocula via a food-borne transmission [23]. Furthermore, the selfmedicated cases with FQ, in our study might result in a lower rate of S. Paratyphi A cases.

FQs and nalidixic-acid are the most prescribed antibiotics against salmonellosis in low-income-countries due to their cost-effectivity, easy accessibility (even sold from the medical pharmacies without a prescription), and availability in oral forms $[7,24,25,30]$. With the emergence 


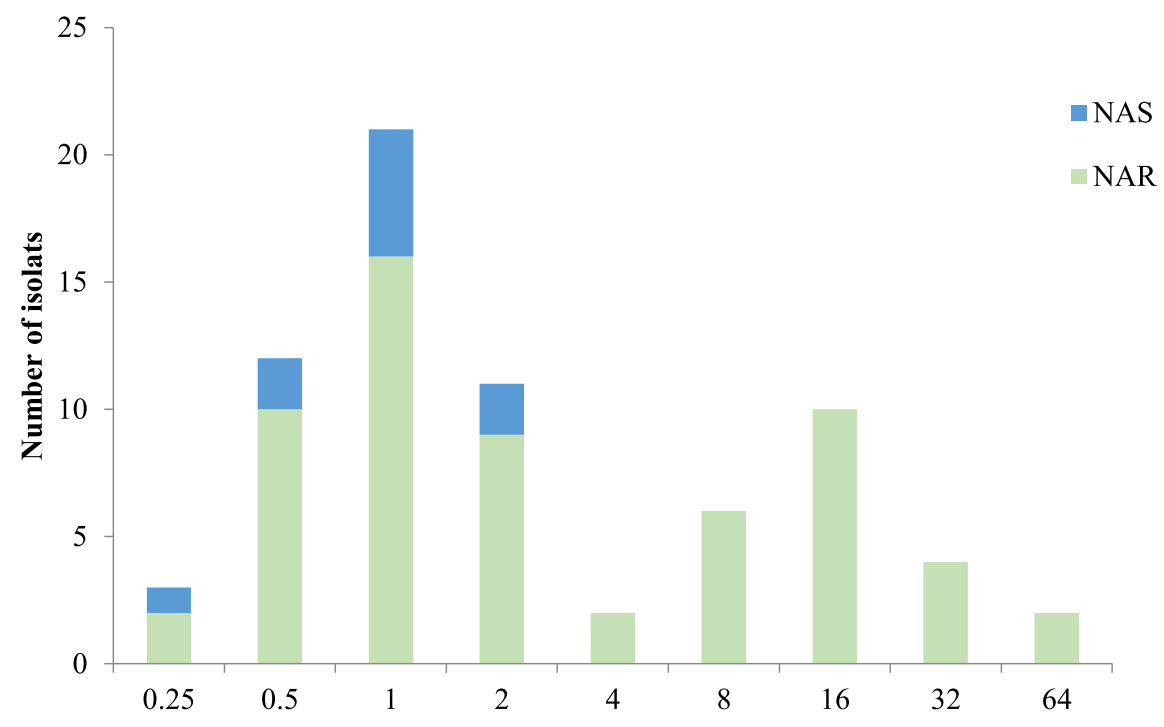

Ciprofloxacin MIC in $\mu \mathrm{g} / \mathrm{ml}$

MIC of Ciprofloxacin among NARS and NASS isolates

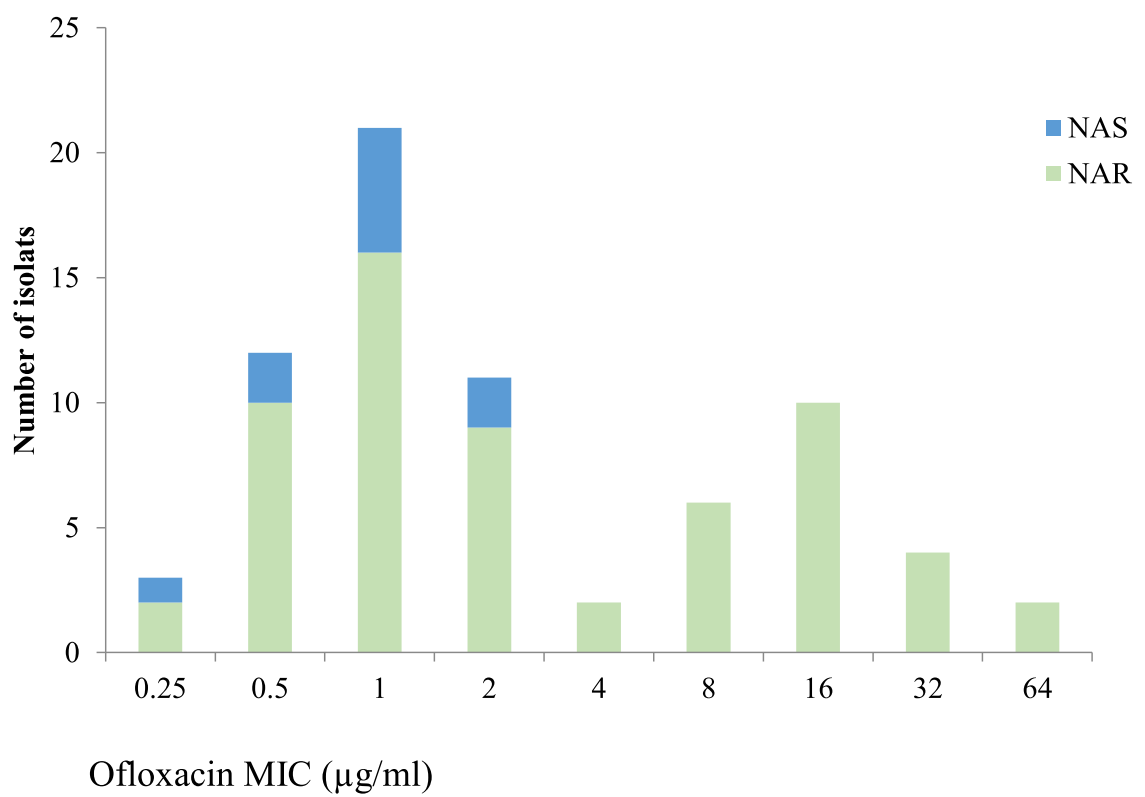

Fig. 2 MICS of FQs (ciprofloxacin and ofloxacin) among NARS and NASS isolate

of NARS strains, globally; however, their efficacy against enteric fever is now questionable [31, 32]. It has been assumed that due to mutation in the genes coding for DNA gyrase (gyrA and gyrB) and topoisomerase IV (parC and parE), a high level of nalidixic-acid resistance occurs [33]. Similarly, lower susceptibility to fluoroquinolones possibly occurs due to the enhanced active efflux and early overproduction of the AcrA pump in isolates with the gyrA mutation [33]. Turning to our study, 304 cases (218 on ciprofloxacin; 86 on ofloxacin) had self-medicated history (treated with-out knowing etiologies and drug resistance pattern); despite, this resistance trend. We observed very high rates of FQs and nalidixic-acid resistance, but relatively low rates of resistance to first-line drugs. The findings are in line with recent epidemiological studies conducted in the Nepalese population [22, 24, 25, 27]. Possibly, due to the discontinuation of the commonly used antibiotics, of these days, in the therapeutic regimen for a longer time, and possibly the 
high molecular weight self-transmissible plasmid inducing resistance could have lost or de novo susceptibility [22, 34].

In our study, among tested antibiotics, a low rate of azithromycin resistance was observed on MIC which is similar to Khanal et al. reported [34]. In the Nepalese population, treatment failure on azithromycin treatment is yet not reported; nevertheless, an increase in MIC was reported in the patients from other countries. Relying upon this background, we can advocate for its choice as empiric therapy against salmonellosis.

Additionally, the third-generation cephalosporins (ceftriaxone, cefotaxime, and cefixime) had shown excellent effectiveness against Salmonella serovars with sensitivity up to $100 \%$ [35, 36]. In our study, $98.8 \%$ of the isolates were sensitive against third-generation cephalosporins supporting their use as well.

Moreover, MDR Salmonella isolates with fluctuating resistance trends have been increasingly reported from Asian countries [21, 28, 37, 38]. In our study subjects, fortuitously, no MDR salmonella isolate was recovered though this has been reported earlier from Nepal [25].

\section{Limitation}

Among self-medicated cases, FQ-sensitive isolates might have failed to grow contributing to the lower incidence; therefore, the exact incidence of the disease could be even greater than observed. Probably, this could be the major drawback of our study. Although, a hospital-based study, we could not evaluate the risk factors and treatment outcomes in our settings. Further, the clinical evaluations of a large study population in the multicentral health institutions, if could have possible, it would be more elucidative. Besides, lacking the molecular laboratory set-up (presumed as a necessity for highquality data in clinical studies) in our settings was another drawback, since blood culture has limited sensitivity.

\section{Conclusion}

Regardless of surging drug-resistant Salmonella enterica cases elsewhere, the level of resistance was not as high as predicted in our study population. MDR trends may vary, therefore drug susceptibility testing side-by-side to empirical therapy is mandatory-particularly in developing countries where there is a practice of selfmedication. Referring to our findings, higher susceptibility of Salmonella enterica to the conventional anti-typhoidal drugs was attributed compared to macrolides and fluoroquinolons. Therefore, reconsideration of these antibiotics as implicated therapies could be useful in clinical management. However, the decreased susceptibility against fluoroquinolones, alone and, in nalidixic-acid-resistance strain negates its empirical use.

\section{Supplementary Information}

The online version contains supplementary material available at https://doi. org/10.1186/s12887-021-02497-3.

Additional file 1: Supplemental Figure 1. Scatter plot relating ciprofloxacin MICs to nalidixic acid MICs and disk. Supplemental Figure 2. Scatter plot relating ofloxacin MICs to nalidixic acid MICs and disk.

\begin{abstract}
Abbreviations
AMR: antimicrobial resistance; ASM: American Society for Microbiology; ATCC: American Type Culture Collection; CLSI: Clinical and Laboratory Standard Institute; MDR: multiple-drug resistant; NARS: nalidixic-acid resistance Salmonella; NASS: nalidixic-acid sensitive Salmonella; $\mathrm{S}$. Typhi: Salmonella Typhi; S. Paratyphi: Salmonella Paratyphi; ZOI: zone of inhibition
\end{abstract}

\section{Acknowledgments}

We are profoundly obliged to all the patients participating in this study. Our special thanks go to all the laboratory staff, management, and officials of International Friendship Children's Hospital Kathmandu for providing the opportunity to carry out this research work.

\section{Authors' contributions}

PK and JT made the diagnosis, designed the manuscript, reviewed the literature, and prepared the article for submission. ST helped with the literature review, gave the concept of the research paper, and critically reviewed the manuscript. All authors read and approved the final manuscript.

\section{Funding}

Not applicable (Nil).

\section{Availability of data and materials}

Data generated or analyzed during this study are included in this manuscript and the remaining are available from the corresponding author on reasonable request.

\section{Ethics approval and consent to participate}

This research was approved by the Institutional Review Committee of International Friendship Children's Hospital, Kathmandu, Nepal. A written informed consent was taken from their parents before participating in the study. Data regarding personal information and existing other infectious disease were coded and kept confidential.

Consent for publication

Not applicable.

Competing interests

The authors declare that they have no competing interests.

Author details

${ }^{1}$ Medical Microbiology, Tri-Chandra Multiple Campus, Kathmandu, Nepal. ${ }^{2}$ International Friendship Children's Hospital, Kathmandu, Nepal.

Received: 16 September 2020 Accepted: 7 January 2021

Published online: 15 January 2021

References

1. Rahman MA, Lorkowski S, et al. Disease and injury incidence and prevalence collaborators G. global, regional, and national incidence, prevalence, and years lived with disability for 354 diseases and injuries for 195 countries and territories, 1990-2017: a systematic analysis for the Gl. Lancet. 2018;392: 1789-858.

2. Roth GA, Abate $\mathrm{D}$, Abate $\mathrm{KH}$, et al. Global, regional, and national age-sexspecific mortality for 282 causes of death in 195 countries and territories, 1980-2017: a systematic analysis for the global burden of disease study 2017. Lancet. 2018;392:1736-88.

3. Britto CD, Dyson ZA, Duchene S, Carter MJ, Gurung M, Kelly DF, et al. Laboratory and molecular surveillance of paediatric typhoidal Salmonella in 
Nepal: antimicrobial resistance and implications for vaccine policy. Plos Negl Trop Dis. 2018;12(4):1-19.

4. Britto C, Pollard AJ, Voysey M, Blohmke CJ. An appraisal of the clinical features of pediatric enteric fever: systematic review and meta-analysis of the age-stratified disease occurrence. Clin Infect Dis. 2017;64(11):1604-11.

5. Dahiya S, Malik R, Sharma P, et al. Current antibiotic use in the treatment of enteric fever in children. Indian J Med Res. 2019;149(2):263-9.

6. Britto $C D$, John J, Verghese VP, et al. A systematic review of antimicrobial resistance of typhoidal Salmonella in India. Indian J Med Res. 2019;149:151-63.

7. Browne AJ, Kashef Hamadani BH, Kumaran EAP, Rao P, Longbottom J, Harriss E, et al. Drug-resistant enteric fever worldwide, 1990 to 2018: a systematic review and meta-analysis. BMC Med. 2020;18(1):1-22.

8. John J, Bavdekar A, Rongsen-Chandola T, et al. Estimating the incidence of enteric fever in children in India: a multi-site, active fever surveillance of pediatric cohorts. BMC Public Health. 2018;18:594. https://doi.org/10.1186/ S12889-018-5498-2.

9. Holt KE, Baker S, Dongol S, Basnyat B, Adhikari N, Thorson S, et al. Highthroughput bacterial SNP typing identifies distinct clusters of Salmonella Typhi causing typhoid in Nepalese children. BMC Infect Dis. 2010;10:1-9.

10. Baker S, Holt KE, Clements AC, et al. Combined high-resolution genotyping and geospatial analysis reveals modes of endemic urban typhoid fever transmission. Open Biol. 2011;1 (2):110008. https://doi.org/10.1098/rsob. 110008.

11. Pokharel BM, Koirala J, Dahal RK, Mishra SK, Khadga PK, Tuladhar NR. Multidrug-resistant and extended-spectrum beta-lactamase (ESBL)producing Salmonella enterica (serotypes Typhi and Paratyphi a) from blood isolates in Nepal: surveillance of resistance and a search for newer alternatives. Int J Infect Dis. 2006;10(6):434-8.

12. Chau TT, Campbell Jl, Galindo CM, Hoang NVM, To SD, Nga TTT, et al. Antimicrobial drug resistance of Salmonella enterica serovar Typhi in Asia and molecular mechanism of reduced susceptibility to the fluoroquinolones. Antimicrob Agents Chemother. 2007;51(12):4315-23.

13. Wong VK, Baker S, Pickard DJ, Parkhill J, Page AJ, Feasey NA, et al. Phylogeographical analysis of the dominant multidrug-resistant $\mathrm{H} 58$ clade of Salmonella Typhi identifies inter-and intracontinental transmission events. Nat Genet. 2015;47(6):632-9.

14. Holt KE, Phan MD, Baker S, et al. Emergence of a globally dominant inchi1 plasmid type associated with multiple drug resistant typhoid. PLoS Negl Trop Dis. 2011;5(7):e1245. https://doi.org/10.1371/journal.pntd.0001245.

15. Msemo OA, Mbwana J, Mahende C, Malabeja A, Gesase S, Crump JA, et al. Epidemiology and antimicrobial susceptibility of salmonella enterica bloodstream isolates among febrile children in a rural district in northeastern Tanzania: a cross-sectional study. Clin Infect Dis. 2019;68(Suppl 2):S177-82.

16. Kelly DF, Thorson S, Maskey M, Mahat S, Shrestha U, Hamaluba M, et al. The burden of vaccine-preventable invasive bacterial infections and pneumonia in children admitted to hospital in urban Nepal. Int J Infect Dis. 2011;15(1): e17-23. https://doi.org/10.1016/j.ijid.2010.05.021.

17. Pradhan R, Shrestha U, Gautam SC, Thorson S, Shrestha K, Yadav BK, et al. Bloodstream infection among children presenting to a general hospital outpatient Clinic in Urban Nepal. Plos One. 2012;7(10):1-7.

18. Isenberg HD. Clinical microbiology procedures handbook. 2nd ed. Washington Dc: ASM Press; 2004.

19. CLSI. Performance standards for antimicrobial susceptibility testing. CLSI supplement M100S. In: Clinical and Laboratory standards Institute. 26th ed. Wayne: Clinical and Laboratory standards Institute; 2016.

20. Andrews JM. Determination of minimum inhibitory concentrations. J Antimicrob Chemother. 2001;48(1):5-16.

21. Karki S, Shakya P. Leder, Karin et al. trends of etiology and drug resistance in enteric fever in the last two decades in Nepal: a systematic review and meta-analysis. Clin Infect Dis. 2013;57(10):167-76.

22. Shrestha KL, Pant ND, Lekhak B, et al. Re-emergence of the susceptibility of the Salmonella spp. isolated from blood samples to conventional first line antibiotics. Antimicrob Resist Infect Control. 2016;5(1):1-5. https://doi.org/10. 1186/s13756-016-0121-8.

23. Acharya D, Bhatta DR, Malla S, Kandel BP, et al. Salmonella enterica serovar Paratyphi a: an emerging cause of febrile illness in Nepal. Nepal Med Coll J. 2011;13(2):69-73.

24. Petersiel N, Shresta S, Tamrakar R, Koju R, Madhup S, Shresta A, et al. The epidemiology of typhoid fever in the Dhulikhel area, Nepal : A prospective cohort study. Plos One 2018;1-8. doi: https://doi.org/10.1371/journal.\% OApone.0204479.

25. Zellweger RM, Basnyat B, Shrestha P, Prajapati KG, Dongol S, Sharma PK, et al. A 23-year retrospective investigation of Salmonella Typhi and Salmonella Paratyphi isolated in a tertiary Kathmandu hospital. Plos Negl Trop Dis. 2017;11(11):1-16.

26. Easow JM, Joseph NM, Dhungel BA, Chapagain B. Shivananda, P G et al. blood stream infections among febrile patients attending a teaching Hospital in Western Region of Nepal. AMJ. 2010;3(10):633-7.

27. Prajapati B, Rai GK, Rai SK, Upreti HC, Thapa M, Singh G, et al. Prevalence of Salmonella typhi and paratyphi infection in children: a hospital based study. Nepal Med Coll J. 2008;10(4):238-41.

28. Shirakawa T, Acharya B, Kinoshita S, Kawabata M, et al. Decreased susceptibility to fluoroquinolones and gyrA gene mutation in the Salmonella enterica serovar Typhi and Paratyphi a isolated in Katmandu, Nepal in 2003. Diagn Microbiol Infect Dis. 2006;54(4):299-303.

29. Pokherel P, Lekhak B, Amatya R, Pokherel P, et al. Enteric fever caused by Salmonella enterica serovar paratyphi a: an emerging health concern in Nepal. African J Microbiol Res. 2016;10(42):1784-91.

30. Humphries RM, Fang FC, Aarestrup FM, Hindler JA. In vitro susceptibility testing of fluoroquinolone activity against salmonella: recent changes to CLSI standards. Clin Infect Dis. 2012:55(8):1107-13.

31. Menezes GA, Harish BN, Khan MA, WG, Hays JP, et al. Antimicrobial resistance trends in blood culture positive Salmonella Typhi isolates from Pondicherry, India, 2005-2009. Clin Microbiol Infect. 2012;18(3):239-45. https://doi.org/10.1111/j.1469-0691.2011.03546x.

32. Acharya D, Malla S, Dumre SP, et al. Multidrug resistant Salmonella enterica serovar typhi. J Nepal Med Assoc. 2009;48(174):196-7.

33. Giraud E, Cloeckaert A, Chaslus-Dancla E, et al. Evidence for active efflux as the primary mechanism of resistance to ciproffoxacin in Salmonella enterica serovar typhimurium. Antimicrob Agents Chemother. 2000;44(5):1223-8.

34. Khanal PR, Satyal D, Bhetwal A, et al. Renaissance of conventional first-line antibiotics in Salmonella enterica clinical isolates: assessment of MICs for therapeutic antimicrobials in enteric fever cases from Nepal. Biomed Res Int. 2017;2017:2868143. https://doi.org/10.1155/2017/2868143.

35. Crump JA, Sjölund-Karlsson M, Gordon MA, Parry CM, et al. Epidemiology, clinical presentation, laboratory diagnosis, antimicrobial resistance, and antimicrobial management of invasive Salmonella infections. Clin Microbiol Rev. 2015;28(4):901-37.

36. Kariuki S, Gordon MA, Feasey N, et al. Antimicrobial resistance and management of invasive Salmonella disease. Vaccine. 2015;33(3):C21-9.

37. Harish BN, Menezes GA, et al. Antimicrobial resistance in typhoidal salmonellae. Indian J Med Microbiol. 2011;29(3):223-9.

38. Threlfall $E J$, Ward $L R$, Rowe $B$, et al. Widespread occurrence of multiple drug-resistant Salmonella typhi in India. Eur J Clin Microbiol Infect Dis. 1992; 11(11):990-3.

\section{Publisher's Note}

Springer Nature remains neutral with regard to jurisdictional claims in published maps and institutional affiliations.

\section{Ready to submit your research? Choose BMC and benefit from:}

- fast, convenient online submission

- thorough peer review by experienced researchers in your field

- rapid publication on acceptance

- support for research data, including large and complex data types

- gold Open Access which fosters wider collaboration and increased citations

- maximum visibility for your research: over $100 \mathrm{M}$ website views per year

At $\mathrm{BMC}$, research is always in progress.

Learn more biomedcentral.com/submissions 